\title{
Frequency of Carpal Tunnel Syndrome in Dentists Working in Government Hospitals of Lahore
}

\author{
Muhammad Adeel Ehsan ${ }^{1}$, Sarah Ehsan ${ }^{2}$, Hafiz Sheraz Arshad ${ }^{3}$ \\ ${ }^{1}$ Physical Therapist, Azra Naheed Medical College, Department of Physical Therapy, Main Raiwind Road, Lahore \\ ${ }^{2}$ Senior lecturer, Azra Naheed Medical College, Department of Physical Therapy, Main Raiwind Road, Lahore
}

${ }^{3}$ Head of Department/Assistant Professor, Azra Naheed Medical College, Department of Physical Therapy, Main Raiwind Road, Lahore

\begin{abstract}
Carpal tunnel syndrome (CTS) is caused due to compression on median nerve, people suffering from carpal tunnel syndrome often experience pain, numbness, tingling sensation and hand weakness. Higher prevalence of Carpal tunnel syndrome has been found in certain vocational groups with repetitive hand movements. Aim of this study was to find the frequency of carpal tunnel syndrome among dentists working in government hospitals of Lahore. A descriptive cross sectional study was conducted in dentists working in government hospitals of Lahore. The diagnosis of CTS was made on the basis of symptoms, numbness, pain, tingling sensation and hand weakness and phalen's test. Data were collected from 109 dentists. Self- administered questionnaires based on demographic questions and symptoms of carpel tunnel syndrome were given to the participants. Out of the 109 dentists103 responded, with a response rate of 94.1\%. Mean age of respondents was 31.68(SD=3.96). Most of the dentists were male $(n=64,62.1 \%)$. The average working hours of the dentists were $5.66(S D=1.1)$. The frequency of dentists having carpal tunnel syndrome was 15.5\%.The study concludes that carpel tunnel syndrome is frequent among dentists working in Hospitals of Lahore. Further studies on ergonomic evaluation of working postures and risk factors associated with CTS among dentists are highly recommended.
\end{abstract}

Keywords: Carpal tunnel syndrome, Dentists, Numbness, Overuse injuries, repetitive trauma

\section{Introduction}

\subsection{Overview}

Carpal tunnel syndrome represents a considerable role of the work related upper extremity disorders[1]. It has been evaluated that every year $70 \%$ dentists reported musculoskeletal pain. Carpal tunnel syndrome has been more revealed in dentists than general population[2].work related reasons include repeatedly bending movements of wrist, hold equipments forcefully with ulnar deviation of hand and sustain compression on palm. These movements are performed during dental surgery and root canal treatment that can cause pressure on median nerve[3].Musculoskeletal pain, especially wrist pain, has been found to be a big health issue for dental practitioners. Many studies have reported a Similar prevalence of musculoskeletalissue among dentists in different region of the world[4]. A major study conducted in Greece demonstrates that $62 \%$ dental practitioners suffering at least one musculoskeletal problem [5]. A study of Minnesota dentists uncovered that $7 \%$ had been diagnosed as having carpal tunnel syndrome, though $63 \%$ reported that they are facing one or more symptoms associated with Carpal tunnel syndrome, Same results were found in California dentists , among whom $6.4 \%$ of those had been diagnosed with carpal tunnel syndrome [6] .A Study conducted in Mangalore Shows that prevalence of carpal tunnel syndrome in dentists is high 20\%[1],Another study conducted on army dental personnel in America indicated that prevalence of carpal tunnel syndrome is high in army dental personnel 25.4\%[7].In Pakistan this study is conducted in Karachi , Khyber pakhtunkhwa and Rawalpindi but never ever conducted in Lahore specially in government hospitals. the prevalence of carpal tunnel syndrome in dentists working in Khyber Pakhtunkhwa was $14 \%$ [8]. And the prevalence of carpal tunnel syndrome in dentists working in Karachi was $10.31 \%$ [5], Outcome from this research could be valuable to be a standard data to build up more study .

\subsection{Objective}

The objective of this study was to find the frequency of carpal tunnel syndrome among dental practitioners working in government hospitals of Lahore.

\subsection{Rationale}

The rational of this study was to create awareness about the occurance of carpal tunnel syndrome among dentists working in government hospitals of Lahore.

\subsection{Operational definitions}

\subsubsection{Phalen's Test}

The frequency of carpal tunnel syndrome was assessed by performing phalen's test.60 studies were conducted on different tests to diagnose the carpal tunnel syndrome according to them the sensitivity of phalen's test was $68 \%$ and specificity was 73\%[9].Another study indicated that sensitivity of phalen's test was 0.97 and 0.92 and specificity of phalen's test was 0.91 and 0.88.[10].

\subsection{Materials and methods}

\subsubsection{Study design}

This was a descriptive, cross-sectional study

\subsubsection{Setting}

- Data was collected from government hospitals of Lahore.

- Punjab Dental hospital

- Data Darbar hospital 


\section{International Journal of Science and Research (IJSR)}

ISSN (Online): 2319-7064

Index Copernicus Value (2013): 6.14 | Impact Factor (2015): 6.391

- Ganga Ram hospital

- Mayo hospital

\subsubsection{Study population}

Dentists working in government hospitals of Lahore

\subsubsection{Duration of study}

The Study was completedin three months duration.

\subsubsection{Sample size}

A sample size of 109 dentists was selected out of 150 dentists working in government hospitals of Lahore, certainty level was $95 \%$ and margin of error was $5 \%$ .Sample size was selected by using this formula.

$$
\begin{aligned}
& x=Z\left({ }^{c} / 100\right)^{2} r(100-r) \\
& n=N x /\left((N-1) E^{2}+x\right) \\
& E=S q r t\left[{ }^{(N-n) x} / n(N-1)\right]
\end{aligned}
$$

\subsubsection{Sampling technique}

Simple random sampling technique was used.

\subsubsection{Eligibility}

\subsubsection{Inclusion criteria}

Data was collected from the dentists

- Age group is 25-45

- Without underlying pathology

- Non obese

- Non smokers,

- Having at least one year of work experience

- Working in government hospitals of Lahore

\subsubsection{Exclusion criteria}

- Pregnancy

- Obesity

- Smokers

- Recent injury that affecting upper limb

- Dentists who were suffering from diabetes, rheumatoid arthritis, thyroid gland disease and wrist fractures and having wrist swelling were excluded.

\subsubsection{Data collection}

This descriptive cross sectional study was conducted on dentists practicing in government hospitals of Lahore. Dentists with age between 25-45 years, having at least one year of clinical experience, having no underlying pathology, non-obese and non-smokers were included in the study. Informed consent was obtained from the participants and the research was conducted between January 2016 and April 2016. A questionnaire was administered to dental practitioners including questions on occupational information of dentists included gender, age, experience, working hours per week, Diagnose was made on the basis of pain, numbness, burning or tingling sensation , pain in wrist at night, nocturnal aggravation of hand symptoms, dropping and difficulty in holding items and hand weakness. Phalen's test was performed to the dentists who were having more than two diagnostic symptoms to confirm the carpal tunnel syndrome.

\subsubsection{Ethical consideration}

Data were taken from dentists after an informed consent. It did not affect the patientethical values;researcher followed all ethics of the medical field.

\subsubsection{Statistical procedure}

Computer program SPSS 17 was used to analyze the collected data. Categorical variables were measured using frequencies and percentages. Quantitative variables were analyzed by using Mean and standard deviation

\section{Results}

Table 1: Descriptive statistics for age and working hours of dentists.

\begin{tabular}{|c|c|c|c|}
\hline & Mean (SD) & Minimum & Maximum \\
\hline Age & $31.68(3.96)$ & 26 & 43 \\
\hline Working hours & $5.66(1.1)$ & 4 & 8 \\
\hline
\end{tabular}

Participants had a Mean age (in years) of $31.68(\mathrm{SD}=3.96)$ with a minimum of 26 and maximum age of 43 . The Mean working hours of respondents were $5.66(\mathrm{SD}=1.1)$.

Table 2: Gender distribution of Dentists

\begin{tabular}{|c|c|c|c|}
\hline \multirow{2}{*}{ Gender } & Male & 64 & 62.1 \\
\cline { 2 - 4 } & Female & 39 & 37.9 \\
\hline
\end{tabular}

Most of the Participants were Males (n=64, 62.1).

Table 3: Frequency of Carpel tunnel syndrome

\begin{tabular}{|c|c|c|c|}
\hline \multicolumn{2}{|c|}{} & Frequency $(\mathrm{n}=103)$ & Percentage (\%) \\
\hline \multirow{2}{*}{ CTS present } & Yes & 16 & 15.5 \\
\cline { 2 - 4 } & No & 87 & 84.5 \\
\hline
\end{tabular}

Out of 103 participants CTS was positive in only $16(15.5 \%)$

Table 4: Numbness in median nerve distribution

\begin{tabular}{|c|c|c|c|}
\hline & & Frequency $(\mathrm{n}=103)$ & Percentage (\%) \\
\hline Numbness in median & Yes & 15 & 14.6 \\
\cline { 2 - 4 } nerve distribution & No & 88 & 85.4
\end{tabular}

Out of 103 participants numbness in median nerve

distribution was present in $15(14.6 \%)$ participants.

Table 5: Numbness in whole hand distribution

\begin{tabular}{|c|c|c|c|}
\hline \multicolumn{2}{|c|}{} & Frequency $(\mathrm{n}=103)$ & Percentage (\%) \\
\hline \multirow{2}{*}{$\begin{array}{c}\text { Numbness in } \\
\text { whole hand }\end{array}$} & Yes & 22 & 21.4 \\
\cline { 2 - 4 } & No & 81 & 78.6 \\
\hline
\end{tabular}

Numbness in whole hand was present in 22(21.4) participants.

Table 6: Nocturnal aggravation of hand symptoms

\begin{tabular}{|c|c|c|c|}
\hline \multicolumn{2}{|c|}{} & Frequency $(\mathrm{n}=103)$ & Percentage (\%) \\
\hline Nocturnal & Yes & 7 & 6.8 \\
\cline { 2 - 4 } aggravation & No & 96 & 93.2 \\
\hline
\end{tabular}

Only $7(6.8 \%)$ participants were facing nocturnal aggravation of hand symptoms.

Table 7: Frequency of pain that can be shaken out at night

\begin{tabular}{|c|c|c|c|}
\hline \multicolumn{2}{|c|}{} & Frequency $(\mathrm{n}=103)$ & Percentage (\%) \\
\hline Pain that can & Yes & 14 & 13.6 \\
\cline { 2 - 4 } be shaken out & No & 89 & 86.4 \\
\hline
\end{tabular}

$14(13.6 \%)$ participants were suffering from pain that can be shaken out. 


\section{International Journal of Science and Research (IJSR) \\ ISSN (Online): 2319-7064 \\ Index Copernicus Value (2013): 6.14 | Impact Factor (2015): 6.391}

Table 8: Frequency of participants having pain after frequent use of hand and wrist

\begin{tabular}{|c|l|c|c|}
\hline \multicolumn{2}{|c|}{} & Frequency $(\mathrm{n}=103)$ & Percentage (\%) \\
\hline Pain after frequent & Yes & 39 & 37.9 \\
\cline { 2 - 4 } use of hand & No & 64 & 62.1 \\
\hline
\end{tabular}

large numbers of participants 39(37.9\%) were complained of pain after frequent use of hand and wrist.

Table 9: Frequency of participants facing difficulty in holding items.

\begin{tabular}{|c|l|c|c|}
\hline \multicolumn{2}{|c|}{} & Frequency $(\mathrm{n}=103)$ & Percentage (\%) \\
\hline \multirow{2}{*}{$\begin{array}{c}\text { Difficulty in } \\
\text { holding items }\end{array}$} & Yes & 13 & 12.6 \\
\cline { 2 - 4 } & No & 90 & 87.4 \\
\hline
\end{tabular}

$13(12.6 \%)$ participants said they are having difficulty in holding items.

Table 10: Distribution of pain referred more proximally in the upper limb

\begin{tabular}{|l|l|l|l|}
\hline \multicolumn{2}{|c|}{} & Frequency $(\mathrm{n}=103)$ & Percentage (\%) \\
\hline Pain referred & Yes & 36 & 35.0 \\
\cline { 2 - 4 } proximally & No & 67 & 65.0 \\
\hline
\end{tabular}

$36(35.0 \%)$ participants said pain referred more proximally in the upper limb.

Table 11: Frequency distribution of phalen's test

\begin{tabular}{|l|l|l|}
\hline & Positive $(\mathrm{n}=103)$ & Negative \\
\hline Phalen's Test & $16(15.5 \%)$ & $87(84.5 \%)$ \\
\hline
\end{tabular}

Phalen's Test was positive in all of the participants suffering from carpal tunnel syndrome.

\section{Discussion}

The present study was conducted on dentists working in government hospitals of Lahore, Same study conducted in Isfahan, Iran [3], America[2] , Karachi[5], And in Riyadh, Saudi Arabia[11].In the present study the mean age was 31.68 years, In another study conducted on dentists in north America the mean age was 38 years[2] In a study conducted in Manglore,India the mean age was 29.05 years[1].Mansoor et al., 2013 conducted the same study on dentists in which the mean age of the participants was 26.8 years[12],Another study that was conducted in KSA in which the mean age was higher as compared to others 47.79 years[11].In the present study $62.1 \%$ were males and $37.9 \%$ were females, Mansoor et al conducted another study in Pakistan in which $60 \%$ were males and $40 \%$ were females[12],In another study conducted in India the females ratio was high as compared to males, $59.1 \%$ were females and $40.1 \%$ were males [1] , Study conducted in Karachi the female dentists percentage was high $59 \%$ and male dentists percentage were $41 \%$ [5], Same study conducted in Khyber pakhtunkhwa in which male to female ratio was 2.6:1[8].In the present study self administered questionnaire and phalen's test was used to assessed the frequency of carpal tunnel syndrome, Mansoor et al used nordotic questionnaire in their study[12], Al Rouq et al performed nerve conduction study to assess the frequency of carpal tunnel syndrome[11],In Karachi KHAN et al used Boston carpal tunnel questionnaire to know the prevalence of carpal tunnel syndrome among dentists working in Karachi[5]In the present Study the frequency of carpal tunnel syndrome was $15.5 \%$, Ayatollahi et al conducted a study on dentists according to them only $5 \%$ dentists were suffering from carpal tunnel syndrome[13],
According to a study conducted in Khyber Pakhtunkhwa the prevalence of carpal tunnel syndrome in dentists was $14 \%[8]$ and prevalence of carpal tunnel syndrome in dentists working in Karachi was only $10.31 \%$ [5],The highest prevalence of carpal tunnel syndrome was fond in dentists working in India that was $20 \%[1]$.

\section{Conclusion}

The study concludes that carpel tunnel syndrome is frequent among dentists working in Hospitals of Lahore. Further studies on ergonomic evaluation of working postures and risk factors associated with CTS among dentists are highly recommended.

\section{References}

[1] MITHUN PAI, B., SHENOY, R., RAJESH, G. \& RAO, A. 2014. Symptoms of Carpal Tunnel Syndrome in a dental work force of a developing country. International Journal of Advanced Research, 2, 87-94.

[2] ANTON, D., ROSECRANCE, J., MERLINO, L. \& COOK, T. 2002. Prevalence of musculoskeletal symptoms and carpal tunnel syndrome among dental hygienists. American journal of industrial medicine, 42, 248-257.

[3] HAGHIGHAT, A., KHOSRAWI, S., KELISHADI, A., SAJADIEH, S. \& BADRIAN, H. 2012a. Prevalence of clinical findings of carpal tunnel syndrome in Isfahanian dentists. Advanced biomedical research, 1

[4] LEGGAT, P. A., KEDJARUNE, U. \& SMITH, D. R. 2007. Occupational health problems in modern dentistry: a review. Industrial health, 45, 611-621.

[5] KHAN, A. A., SIDDIQUI, A. Z., AHMED, M. R., ASKARI, H. \& ZAHID, A. 2014. PREVALENCE OF CARPEL TUNNEL SYNDROME IN THE DENTISTS WORKING IN KARACHI. Pakistan Oral \& Dental Journal, 34.

[6] LALUMANDIER, J. \& MCPHEE, S. 2001. Prevalence and risk factors of hand problems and carpal tunnel syndrome among dental hygienists. Journal of Dental Hygiene, 75, 130-134.

[7] LALUMANDIER, J. A. 2000. Carpal tunnel syndrome: effect on Army dental personnel. Military medicine, 165,372 .

[8] REHMAN, K., AYAZ, H., UROOJ, W. \& SHAH, R. 2013. Work-related musculoskeletal disorders among dental practitioners in Khyber Pakhtunkhwa. Pakistan Oral \& Dental Journal, 33.

[9] MACDERMID, J. C. \& WESSEL, J. 2004. Clinical diagnosis of carpal tunnel syndrome: a systematic review. Journal of Hand Therapy, 17, 309-319.

[10] LAJOIE, A. S., MCCABE, S. J., THOMAS, B. \& EDGELL, S. E. 2005. Determining the sensitivity and specificity of common diagnostic tests for carpal tunnel syndrome using latent class analysis. Plastic and reconstructive surgery, 116, 502-507.

[11] AL ROUQ, F., AHMED, T. S., MEO, I. M., ALDREES, A. M. \& MEO, S. A. 2014. Distribution of clinical symptoms in carpal tunnel syndrome. Journal of the College of Physicians and Surgeons Pakistan, 24, 30-33

\section{Volume 5 Issue 5, May 2016




\section{International Journal of Science and Research (IJSR) \\ ISSN (Online): 2319-7064}

Index Copernicus Value (2013): 6.14 | Impact Factor (2015): 6.391

[12] MANSOOR, S. N., RATHORE, F. A., AZAD, A. A. \& ISHFAQUE, Q. 2013. Frequency of musculoskeletal disorders among dental professionals at armed forces institute of dentistry. JPDA, 22.

[13] AYATOLLAHI, J., AYATOLLAHI, F., ARDEKANI, A. M., BAHROLOLOOMI, R., AYATOLLAHI, J., AYATOLLAHI, A. \& OWLIA, M. B. 2012a. Occupational hazards to dental staff. Dental research journal, 9, 2.

\section{Author Profile}

Muhammad AdeelEhsan is Physical Therapist, Azra Naheed Medical College, Department of Physical Therapy, Main Raiwind Road,, Lahore

Sarah Ehsan is Senior Lecturer, Azra Naheed Medical College, Department of Physical Therapy, Main Raiwind Road,, Lahore

Hafiz SherazArshad is Head of Department/Assistant Professor, Azra Naheed Medical College, Department of Physical Therapy, Main Raiwind Road,, Lahore 